\title{
Variabilidade espacial da fertirrigação em Latossolo Vermelho Amarelo cultivado com melão ${ }^{1}$
}

\author{
Neyton de O. Miranda ${ }^{2}$, Teógenes S. de Oliveira ${ }^{3}$, José de A. de Matos $^{2} \&$ Ariana Carvalho Pinto ${ }^{2}$
}

\begin{abstract}
RESUMO
Este trabalho, realizado em Mossoró, RN, investigou a variabilidade de parâmetros da fertirrigação por gotejamento, sua dependência espacial e correlação com a produtividade e qualidade de frutos de melão. Em uma malha de 20 por $20 \mathrm{~m}$ foram tomadas 75 amostras, para se determinar: produção de frutos tipo exportação (PEXP), mercado nacional (PNAC) e comerciável (PCOM), peso médio de frutos comerciáveis (PMCOM), teor de sólidos solúveis totais (SST), firmeza de polpa, espessura da polpa (ESPOLP), elevação, distância até a entrada de água, além da quantidade de adubo aplicada e vazão dos gotejadores com os respectivos coeficientes de uniformidade de emissão (CUE). A variabilidade foi determinada através da estatística descritiva e da geoestatística. A vazão e a quantidade de adubo aplicada no primeiro teste, foram menores que o esperado. O CUE foi bom e excelente para vazão, e regular e bom para a quantidade de adubo aplicada. A dependência espacial foi observada para vazão e quantidade de adubo aplicada, cujas isolinhas permitiram localizar-se áreas onde ocorreu déficit ou excesso. As correlações sugerem influência da vazão sobre PNAC, PCOM e PMCOM, e da quantidade de adubo sobre PEXP e ESPOLP.
\end{abstract}

Palavras-chave: Cucumis melo L., produtividade, qualidade de frutos, geoestatística

\section{Spatial variability of fertirrigation in a Oxissol cultivated with melon}

\begin{abstract}
This study investigated the variability of drip fertirrigation parameters, its spatial dependence and relationship to yield and quality of melon fruits in a field in Mossoró, RN, Brazil. A total of 75 plots were sampled in a 20 by $20 \mathrm{~m}$ grid to determine the following parameters: yield of export type melon (PEXP) and national market type (PNAC), marketable yield (PCOM), mean weight of marketable fruits (PMCOM), total soluble solids content (SST), pulp firmness, pulp thickness (ESPOLP), emitter discharge rate, elevation, distance to water inlet, amount of fertilizer applied, and emission uniformity (CUE) of discharge rate and fertilizer amount. The variability was assessed by conventional statistics methods and by geostatistics. Fertilizer amount applied in the first test and emitter discharge rate were lower than expected. Emission uniformity was good and excellent for discharge rate, and fair and good for fertilizer amount. Spatial dependence was observed for discharge rate and fertilizer amount, and the maps generated allowed the identification of spots in the field with application deficit or excess application. Correlation analysis suggests influence of discharge rate on PNAC, PCOM and PMCOM, and of fertilizer amount on PEXP and pulp thickness.
\end{abstract}

Key words: Cucumis melo L., fruit yield, fruit quality, geoestatistics

1 Parte da Tese de Doutorado do primeiro autor junto ao Curso de Pós-Graduação em Agronomia-Fitotecnia da UFC

2 Departamento de Ciências Ambientais/UFERSA. CEP 59625-900, Mossoró-RN. Fone: (84) 3315.1799. E-mail: neyton@ufersa.edu.br; jamatos@ufersa.edu.br

${ }^{3}$ Departamento de Ciências do Solo/UFC, Bloco 807, Campus do Pici, CEP 60455-760, Fortaleza-CE. Fone: (085) 4008-9693. E-mail: teo@ufc.br 


\section{INTRODUÇÃO}

A amostragem detalhada de um campo agrícola pode detectar regiões onde a produtividade das culturas é determinada pela aplicação adequada, excessiva ou deficiente de insumos. Constatada a relação de causa e efeito entre produtividade e fatores de produção, o campo deverá ser gerenciado a um nível de resolução menor, com a aplicação das práticas de manejo, conforme os fatores envolvidos (Plant et al., 1999). Como o fator que mais se correlaciona com a produtividade das culturas é a disponibilidade de água e de nitrogênio (Li et al., 2002), o manejo adequado da irrigação proporciona suprimento adequado de água, melhor utilização dos nutrientes pelas plantas e maior produtividade (Upadhyaya et al., 1999) em razão de que é melhor adotar sistemas com altas uniformidades de aplicação de água que aplicá-la em maiores quantidades. Em geral, apenas culturas de alto valor econômico justificam o maior consumo de água com preço elevado e os maiores custos de investimento e operação em sistemas mais eficientes (Seginer, 1978; Solomon, 1979; Walker, 1979).

A combinação das variabilidades espaciais do solo e da aplicação de fertilizantes e de água, causa variação dentro de um campo na produtividade de uma cultura irrigada (Gonçalves et al., 1999), porém se aplica uma mesma lâmina média em todo o campo, ignorando-se a variabilidade do armazenamento de água no solo (Warrick et al., 1987; Fietz et al., 1999). Devido à desuniformidade dos sistemas de irrigação, ocorrerá percolação na metade do campo enquanto na outra metade a irrigação será deficiente, com conseqüentes perdas de produção, além de prejuízos para a cultura e para o solo, quando se aplicam produtos químicos através da irrigação (Walker, 1979; Mantovani et al., 1995; Fietz et al., 1999). O excesso de água causa perdas em produtividade e qualidade dos produtos, provoca o encharcamento, a salinização e a percolação de água, na qual a lixiviação de nutrientes representa perda econômica direta, podendo contaminar o lençol freático (Solomon, 1979; Burt et al., 1997; Fietz et al., 1999).

O modo de aplicação dos fertilizantes é tão importante para a produtividade das culturas quanto a dose utilizada, motivo pelo qual a fertirrigação é mais eficiente que a adubação convencional, sobretudo por não aplicar concentrações altas de nutrientes; no entanto, para se realizar a fertirrigação através de sistemas localizados requer-se uma uniformidade de distribuição de água maior que $80 \%$ (ASAE, 1994; Souza et al., 2003). Na proposição do nível de uniformidade do sistema e na quantidade ótima e econômica de irrigação, deve-se considerar a resposta da cultura à aplicação desuniforme de água e nutrientes (Sadler et al., 2002; Li \& Rao, 2003), a qual tem sido pequena em experimentos de campo (Li \& Rao, 2003). Em simulações, Seginer (1978) e Pinto et al. (1988) demonstraram o efeito da uniformidade de distribuição da água sobre a produtividade. Mantovani et al. (1995) indicaram o aumento na quantidade de água requerida para atingir a produtividade máxima a medida em que diminui a uniformidade de distribuição e a validade da maior aplicação para compensar perdas de produtividade, quando o preço da água é baixo em relação ao preço do produto.

Em sistemas com uniformidade de distribuição semelhante, a distribuição espacial das lâminas superiores ou inferiores pode ser diferente, podendo haver concentração em uma região ou distribuição aleatória (Clemmens \& Solomon, 1997). As funções de probabilidade com distribuição normal informam a possibilidade de certa lâmina ser aplicada podendo-se conhecer volumes de excesso e de déficit, mas não o local onde ocorrem (Evans et al., 1995; Gonçalves et al., 1999); por isto, os cálculos tradicionais da uniformidade de distribuição não são adequados ao manejo da água e nutrientes em áreas específicas, que visam aplicá-los de acordo com as condições do solo e as necessidades da cultura, em cada local do campo (Evans et al., 1995; Burt et al., 1997; Li et al., 2002). A partir de um número considerável grande de observações, pode-se gerar, por interpolação, mapas da capacidade de armazenamento do solo e da distribuição da água e nutrientes, para identificar possíveis áreas com excesso ou déficit de aplicação e, ainda, adotar práticas de manejo para corrigi-las (Evans et al., 1995; Gonçalves et al., 1999).

Os primeiros estudos sobre irrigação em locais específicos, avaliaram-se os efeitos da desuniformidade da irrigação e se observou, a variação espacial da resposta das culturas, visando ao projeto e manejo em solos espacialmente variáveis. Mais recentemente, a resposta das culturas a taxas variáveis de irrigação foi estudada através de equipamentos que permitem aplicar-se, em uma mesma área quantidades variáveis de água e nutrientes (Fraisse et al., 1995; Sadler et al., 2002). Sadler et al. (2002) recomendam a previsão, durante o projeto do sistema de irrigação de um campo, de várias zonas menores de manejo diferenciado e diversas taxas de aplicação, porém salientam que apenas uma grande variação de produtividade sob condições de irrigação pode justificar a adoção do manejo localizado da aplicação de nutrientes.

Objetivou-se, através deste trabalho, identificar e quantificar a variabilidade espacial da fertirrigação, determinar sua dependência espacial e correlacioná-la com componentes de produção e características de qualidade de frutos de melão, de forma a identificar possíveis fatores limitantes, para futura sugestão de práticas de manejo localizado, que possibilitem redução de custos e danos ambientais.

\section{MATERIAL E MÉTODOS}

O trabalho foi desenvolvido entre agosto e novembro de 2002, em área de cultivo comercial da Fazenda São João, em Mossoró, RN, com coordenadas geográficas: 0509' 59,55” de latitude Sul, $37^{\circ} 24^{\prime}$ 39,92” de longitude Oeste e altitude de 29 m. O solo é um Latossolo Vermelho-Amarelo Eutrófico, cujos resultados da análise em 75 locais, na camada de 0 a 30 cm, foram: $\mathrm{pH}$ em $\mathrm{CaCl}_{2}$ de 6,8; 16,5 g dm${ }^{-3}$ de matéria orgânica; $126,1 \mathrm{mg} \mathrm{dm}^{-3}$ de $\mathrm{P} ; 23,7 \mathrm{mmol}_{\mathrm{c}} \mathrm{dm}^{-3}$ de $\mathrm{K} ; 87,1 \mathrm{mmol}_{\mathrm{C}} \mathrm{dm}^{-3}$ de Ca; 28,8 $\mathrm{mmol}_{\mathrm{c}} \mathrm{dm}^{-3}$ de $\mathrm{Mg}$; 12,2 mmol $_{\mathrm{C}} \mathrm{dm}^{-3}$ de Na; 43,9 $\mathrm{g} \mathrm{kg}^{-1}$ de areia; $18,2 \mathrm{~g} \mathrm{~kg}^{-1}$ de silte; $49,7 \mathrm{~g} \mathrm{~kg}^{-1}$ de argila e densidade de $1,51 \mathrm{Mg} \mathrm{m}^{-3}$. 
O melão amarelo, híbrido Goldex, foi semeado em bandejas e as mudas transplantadas após doze dias. Para se obter uma população de 16.667 plantas ha-1, as linhas foram espaçadas 2,0 m e, a cada $50 \mathrm{~cm}$ de linha, duas plantas eram dispostas a $10 \mathrm{~cm}$ uma da outra, sendo que a cada terceiro espaçamento se punha apenas uma planta. Os tratamentos fitossanitários, as capinas e a quantidade de nutrientes fornecida, seguiram o sistema de produção da empresa.

Cada subunidade do sistema de irrigação localizada por gotejamento tinha 48 mangueiras de $100 \mathrm{~m}$ de comprimento no sentido norte-sul, abastecidas duas a duas por linha terciária entre elas. Os tubos gotejadores com emissores não autocompensantes do tipo labirinto, inseridos na mangueira durante a fabricação com espaçamento de $50 \mathrm{~cm}$, estavam sendo usados pela segunda vez. A vazão esperada a uma pressão de $98 \mathrm{kPa}$ na extremidade das mangueiras era de 2,27 $\mathrm{L} \mathrm{h}^{-1}$; a pressão máxima de operação era de $245 \mathrm{kPa}$ nos registros de abertura das quadras. O manejo da irrigação se baseou na evapotranspiração de referência, calculada pelo método de Penman Monteith com dados da Estação Climatológica da Escola Superior de Agricultura de Mossoró - ESAM. Aplicou-se uma lâmina bruta de irrigação de 322,8 mm, entre 11 e 79 dias após semeadura (DAS). Na fertirrigação, a injeção dos fertilizantes foi feita através de bomba injetora de acionamento hidráulico com vazão nominal de $250 \mathrm{~L} \mathrm{ha}^{-1}$; até 77 DAS, foram fornecidos $69,8 \mathrm{~kg} \mathrm{ha}^{-1}$ de $\mathrm{N}, 135,5 \mathrm{~kg} \mathrm{ha}^{-1}$ de $\mathrm{P}_{2} \mathrm{O}_{5}$, 266,2 kg ha-1 de $\mathrm{K}_{2} \mathrm{O}, 1,4 \mathrm{~kg} \mathrm{ha}^{-1}$ de B, 1,3 $\mathrm{kg} \mathrm{ha}^{-1}$ de $\mathrm{MgO}$ e 9,4 $\mathrm{kg} \mathrm{ha}^{-1}$ de $\mathrm{S}$.

A malha de amostragem tinha espaçamento regular de 20 m e seus nós centralizavam 75 parcelas constituídas de uma fileira com $10 \mathrm{~m}$ de comprimento $\left(20 \mathrm{~m}^{2}\right)$. A vazão dos gotejadores foi determinada em quatro gotejadores por parcela, durante dois minutos, com duas repetições, usando-se proveta com divisões de $2 \mathrm{~mL}$. Os resultados de elevação de cada parcela, a qual foi determinada com nível topográfico e régua, foram expressos em relação à parcela de maior elevação, considerada $100 \mathrm{~m}$. A distância desde a entrada de água até a parcela foi definida em metros de tubulação, enquanto os coeficientes de uniformidade de emissão (CUE) foram calculados pela relação entre a média de $25 \%$ das observações que apresentaram os menores valores e a média de todas as observações (Frizzone, 1992).

Realizaram-se dois testes de distribuição de adubo em 24 parcelas, em que no primeiro teste se aplicaram $10,70 \mathrm{~kg} \mathrm{ha}{ }^{-1}$ de adubo (4,10 kg de $\mathrm{HNO}_{3}, 3,30 \mathrm{~kg}$ de $12-$ 02-43 e 3,30 kg de 04-00-48) e, no segundo, 5,86 kg ha-1 de $\mathrm{KCl}$. A determinação da quantidade de adubo aplicada foi realizada de maneira semelhante à usada por Li \& Rao (2003). Mediu-se o volume coletado em recipientes embaixo dos gotejadores, durante todo o tempo de irrigação e se retiraram amostras para determinar a condutividade elétrica (CE). Em laboratório, obtiveram-se equações que relacionavam as concentrações de adubo com a CE da solução, as quais foram usadas para indicar a concentração de adubo em cada recipiente. A quantidade de adubo aplicada foi determinada com os dados de concentração e de volume coletado. As equações obtidas foram:

$$
\begin{gathered}
\text { - Teste 1: Concentração }\left(\mathrm{g} \mathrm{L}^{-1}\right)=0,0000003 \mathrm{CE}^{2}+0,0013 \mathrm{CE}-0,5678 \\
\mathrm{R}^{2}=0,99 \\
\text { - Teste 2: Concentração }\left(\mathrm{g} \mathrm{L} \mathrm{L}^{-1}\right)=0,0005 \mathrm{CE}-0,2624 \\
\mathrm{R}^{2}=0,99
\end{gathered}
$$

Os frutos colhidos foram classificados nos tipos exportação (PEXP) e mercado nacional (PNAC) determinou-se, de cada um, número e peso por parcela, através de balança digital com capacidade de $30 \mathrm{~kg}$ e resolução de $10 \mathrm{~g}$. A produção de frutos comerciáveis (PCOM) foi a soma dos dois tipos enquanto as determinações de qualidade realizadas foram: espessura da polpa através de paquímetro; firmeza de polpa (ESPOLP) com o emprego de penetrômetro com "plunger” de $8 \mathrm{~mm}$ de diâmetro e conteúdo de sólidos solúveis totais (SST) determinado em refratômetro.

Usou-se a estatística descritiva visando analisar o comportamento dos dados e identificar valores discrepantes; para isto determinaram-se: média, mediana, máximo, mínimo, amplitude total, quartil inferior, quartil superior, amplitude interquartílica, variância, desvio padrão, coeficiente de variação (CV), assimetria e curtose, além da correlação de Spearman entre as variáveis da fertirrigação e as de produtividade e qualidade de frutos. A aderência dos dados à distribuição normal foi verificada pelo teste de Shapiro-Wilk a 5\% de probabilidade. As análises geoestatísticas, através dos softwares GeoEAS 1.2.2 (Englund \& Sparks, 1991) e Variowin (Pannatier, 1996) foram utilizadas para avaliar a dependência espacial das variáveis estudadas e confeccionar mapas de isovalores através de interpolação por krigagem.

\section{RESULTADOS E DISCUSSÃO}

A Tabela 1 apresenta a estatística descritiva das variáveis referentes à irrigação; nota-se que, praticamente, as médias e medianas coincidiram, indicando simetria e normalidade dos dados, a qual exigida pela estatística convencional, porém nem todas as variáveis se ajustaram à distribuição normal conforme o teste de Shapiro-Wilk. Os gotejadores apre-

\begin{tabular}{|c|c|c|c|c|c|}
\hline Estatística & $\begin{array}{l}\text { Vazão } \\
\text { L h}^{-1}\end{array}$ & $\begin{array}{c}C E_{1}{ }^{1} \\
\text { dS } \mathrm{m}^{-2}\end{array}$ & $\begin{array}{c}\mathrm{QAD}_{1} \\
\mathrm{~kg} \mathrm{ha}^{-1}\end{array}$ & $\begin{array}{c}\mathrm{CE}_{2} \\
\mathrm{dS} \mathrm{m}^{-2}\end{array}$ & $\begin{array}{c}\mathrm{QAD}_{2} \\
\mathrm{~kg} \mathrm{ha}^{-1}\end{array}$ \\
\hline Média & 2,07 & 1,06 & 10,09 & 1,06 & 5,86 \\
\hline Mediana & 2,06 & 1,06 & 10,19 & 1,06 & 6,04 \\
\hline Mínimo & 1,67 & 1,03 & 6,99 & 0,97 & 3,04 \\
\hline Máximo & 2,47 & 1,12 & 13,43 & 1,12 & 7,38 \\
\hline Quartil inferior & 1,92 & 1,05 & 9,65 & 1,04 & 5,64 \\
\hline Quartil superior & 2,19 & 1,07 & 10,68 & 1,07 & 6,40 \\
\hline Desvio padrão & 0,17 & 0,02 & 1,34 & 0,03 & 0,96 \\
\hline $\mathrm{CV}(\%)^{2}$ & 8,43 & 1,94 & 13,28 & 2,70 & 16,32 \\
\hline Assimetria & 0,09 & 0,85 & $-0,04$ & $-0,69$ & $-1,19$ \\
\hline Curtose & $-0,52$ & 0,81 & 1,40 & 3,95 & 2,07 \\
\hline $\mathrm{W}^{3}$ & $0,98^{\mathrm{ns}}$ & $0,95^{\mathrm{ns}}$ & $0,96^{\mathrm{ns}}$ & $0,89 *$ & $0,91^{*}$ \\
\hline Observações & 71 & 24 & 24 & 24 & 24 \\
\hline
\end{tabular}
sentaram vazão média de 2,07 $\mathrm{L} \mathrm{h}^{-1}$, diferente da esperada

Tabela 1. Estatística descritiva da vazão, condutividade elétrica da solução e quantidade de adubo aplicada no melão Goldex

${ }_{1} \mathrm{CE}_{1}, \mathrm{CE}_{2}, \mathrm{QAD}_{1}$ e $\mathrm{QAD}_{2}$ são as condutividades elétricas e quantidades de adubo recebidas nos testes 1 e 2; ${ }^{2}$ Coeficiente de variação; ${ }^{3}$ Valores calculados do teste Shapiro-Wilk. ns não significativo. * significativo a $5 \%$ de probabilidade. 
$\left(2,27 \mathrm{~L} \mathrm{~h}^{-1}\right)$. Esta diferença se deve a fatores construtivos e à variação de pressão por diferenças de nível e perda de carga nas tubulações (Frizzone, 1992). A distribuição de freqüências foi simétrica (assimetria de 0,09 ) com pequeno achatamento demonstrado pela curtose de - 0,52 e se ajustou à normalidade. $\mathrm{O}$ baixo coeficiente de variação $(\mathrm{CV})$ de 8,43\% é atribuído ao pouco uso dos gotejadores.

A média das condutividades elétricas (CE) das soluções foi $1,06 \mathrm{dS} \mathrm{m} \mathrm{m}^{-1}$ nos dois testes e as distribuições de freqüências assimétricas, à direita no primeiro teste $(0,85)$ e à esquerda no segundo $(-0,69)$. As curvas agudas (curtoses de 0,81 e 3,95) indicam grande concentração dos dados ao redor da média sendo que, no segundo teste, não houve ajuste em relação à normalidade. Os baixos CV sugerem não haver influencia das concentrações da solução sobre as quantidades de adubo aplicadas.

Em relação à quantidade calculada, a quantidade de adubo aplicada foi inferior no primeiro teste $(10,09$ contra $\left.10,70 \mathrm{~kg} \mathrm{ha}^{-1}\right)$ e igual no segundo $\left(5,86 \mathrm{~kg} \mathrm{ha}^{-1}\right)$. As diferenças observadas resultam de imprecisões acumuladas desde a maneira como adubo e água são medidos e diluídos, até a homogeneização deficiente do adubo, citada por Sampaio et al. (1996). A distribuição de freqüências foi simétrica no primeiro teste (assimetria de -0,04) e assimétrica à esquerda, no segundo $(-1,19)$, cujos dados não se ajustaram à normalidade. As curvas agudas, com curtoses de 1,40 e 2,07, mostram grande concentração dos dados ao redor da média. Os CVs foram baixos e médios (13,28\% e 16,32 \%), em desacordo com os obtidos por Souza et al. (2003) na determinação da distribuição espacial de fertilizantes (35 a 65\%).

Na Tabela 2 estão os coeficientes de uniformidade de emissão (CUE) das vazões, condutividades elétricas da solução e quantidades de adubo aplicadas por subunidade de irrigação. A vazão mostrou uniformidade boa e excelente (87 a 91\%) acima, portanto, dos $80 \%$ necessários para se recomendar a injeção de fertilizantes através do sistema de microirrigação, conforme ASAE (1994).

A excelente uniformidade das CE (Tabela 2), característica da bomba injetora de acionamento hidráulico (Zanini \& Olitta, 1987; Sampaio et al., 1996), indica que as concentrações finais foram praticamente iguais em todos os pontos de coleta e exerceram pequeno efeito sobre a uniformidade da concentração da solução e, ainda, que a quantidade de fertilizante aplicada em cada gotejador depende quase que exclusivamente do volume aplicado (Sampaio et al.,1996; Li

Tabela 2. Uniformidade de emissão (CUE) da vazão, condutividade elétrica da solução e quantidade de adubo aplicada nas subunidades de irrigação cultivadas com melão

\begin{tabular}{lcccc}
\hline \multirow{2}{*}{ Subunidade } & $\mathbf{1}$ & $\mathbf{2}$ & $\mathbf{3}$ & Geral \\
\cline { 2 - 5 } & \multicolumn{4}{c}{ CUE $^{1}(\%)$} \\
Vazão $\left(\mathrm{L} \mathrm{h}^{-1}\right)$ & 87,39 & 89,80 & 91,80 & 89,34 \\
$\mathrm{CE}^{-1}\left(\mathrm{dS} \mathrm{m}^{-1}\right)$ & 97,97 & 97,61 & 98,71 & 97,84 \\
$\mathrm{QAD}^{1}\left(\mathrm{~kg} \mathrm{ha}^{-1}\right)$ & 74,06 & 95,04 & 85,04 & 83,24 \\
$\mathrm{CE}^{2}\left(\mathrm{dS} \mathrm{m}^{-1}\right)$ & 95,99 & 99,14 & 96,66 & 97,12 \\
$\mathrm{QAD}^{2}\left(\mathrm{~kg} \mathrm{ha}^{-1}\right)$ & 66,48 & 90,42 & 82,17 & 77,52 \\
\hline${ }^{1} \mathrm{CUE}$ é o coeficiente de uniformidade de emissão; $\mathrm{CE}^{1}, \mathrm{CE}^{2}, \mathrm{QAD}^{1} \mathrm{e}$ QAD $^{2}$ são as condutividades elétricas
\end{tabular}

e quantidades de adubo aplicadas nos testes 1 e 2
\& Rao, 2003). Pelo mesmo motivo, Zanini \& Olitta (1997) atribuíram a redução linear da quantidade de adubo aplicada do início para o fim da linha, à diminuição das vazões por perda de carga. O CUE geral da área das quantidades de adubo aplicadas (Tabela 2) foi menor no segundo teste que no primeiro (83 e $77 \%$ ), sendo que, a primeira subunidade, mais a norte, teve uniformidades baixas nos dois testes (74 e 66\%), fato pode ocorrer quando o tempo de aplicação é pequeno e não há lavagem das tubulações após a injeção (Souza et al., 2003); mesmo assim, a uniformidade do teor de nutrientes nas plantas da área é passível de ser maior que a da fertirrigação, como observado por Li \& Rao (2003).

Tem-se, na Tabela 3, os parâmetros dos modelos ajustados aos semivariogramas das vazões dos gotejadores e das quantidades de adubo aplicadas. Uma forte dependência espacial, com ajuste ao modelo esférico, foi constatada para a vazão dos gotejadores e quantidade de adubo aplicada no primeiro teste (Figura 1), enquanto no segundo teste o modelo foi o exponencial. Os gotejadores não autocompensantes são afetados por fatores espacialmente variáveis, como a elevação e a distância até a entrada de água.

Tabela 3. Parâmetros dos modelos ajustados aos semivariogramas das vazões dos gotejadores e das quantidades de adubo aplicadas em área plantada com melão

\begin{tabular}{lccccc}
\hline Variável & Modelo & $\mathbf{C o}^{1}$ & $\left(\mathbf{C}_{0}+\mathbf{C}_{1}\right)^{2}$ & $\mathbf{A}^{3}$ & $\mathbf{C}_{0} /\left(\mathbf{C}_{0}+\mathbf{C}_{1}\right)^{4}$ \\
Vazão & Esférico & 0,000 & 0,030 & 32,40 & $<1 \%$ \\
Adubo 1 & Esférico & 0,240 & 1,638 & 67,00 & $15 \%$ \\
Adubo 2 & Exponencial & 0,026 & 1,084 & 141,00 & $3 \%$ \\
\hline
\end{tabular}

${ }^{1}$ Efeito Pepita; ${ }^{2}$ Patamar; ${ }^{3}$ Alcance (m); ${ }^{4}$ Relação efeito pepita/patamar.

As isolinhas da vazão e da elevação da área se acham na Figura 2, não se observando relação entre eles. Predominam áreas com déficit de irrigação, cujos maiores déficits se encontram no canto inferior esquerdo, subindo pela lateral esquerda até a ordenada de $150 \mathrm{~m}$ e se expandindo para toda a parte superior do mapa. As maiores vazões estão localizadas na parte inferior direita do mapa, com coordenadas X: 50 a $106 \mathrm{~m}$ e Y: 0 a $150 \mathrm{~m}$, porém se constatou excesso apenas em uma pequena região, no canto inferior direito. As isolinhas das quantidades de adubo aplicadas nos dois testes mostram as regiões de cada área que receberam adubo em excesso ou menos que o planejado. Essas áreas são semelhantes nos dois testes e também se assemelham às isolinhas das vazões, confirmado pelas correlações da Tabela 4. As regiões que receberam mais adubo estão situadas na lateral direita da parte inferior do mapa, enquanto as que receberam menos se acham no canto inferior esquerdo do mapa, com valores menores que o planejado, predominando na lateral esquerda; já no segundo teste a área com quantidades aplicadas em excesso é maior, estendendo-se da lateral inferior direita, em direção ao centro da área e à lateral esquerda, além de outra área com excesso no canto superior esquerdo.

Tem-se, na Tabela 4 as correlações entre as variáveis da fertirrigação e algumas características de produção e qualidade do meloeiro. Os locais das maiores vazões coincidiram 

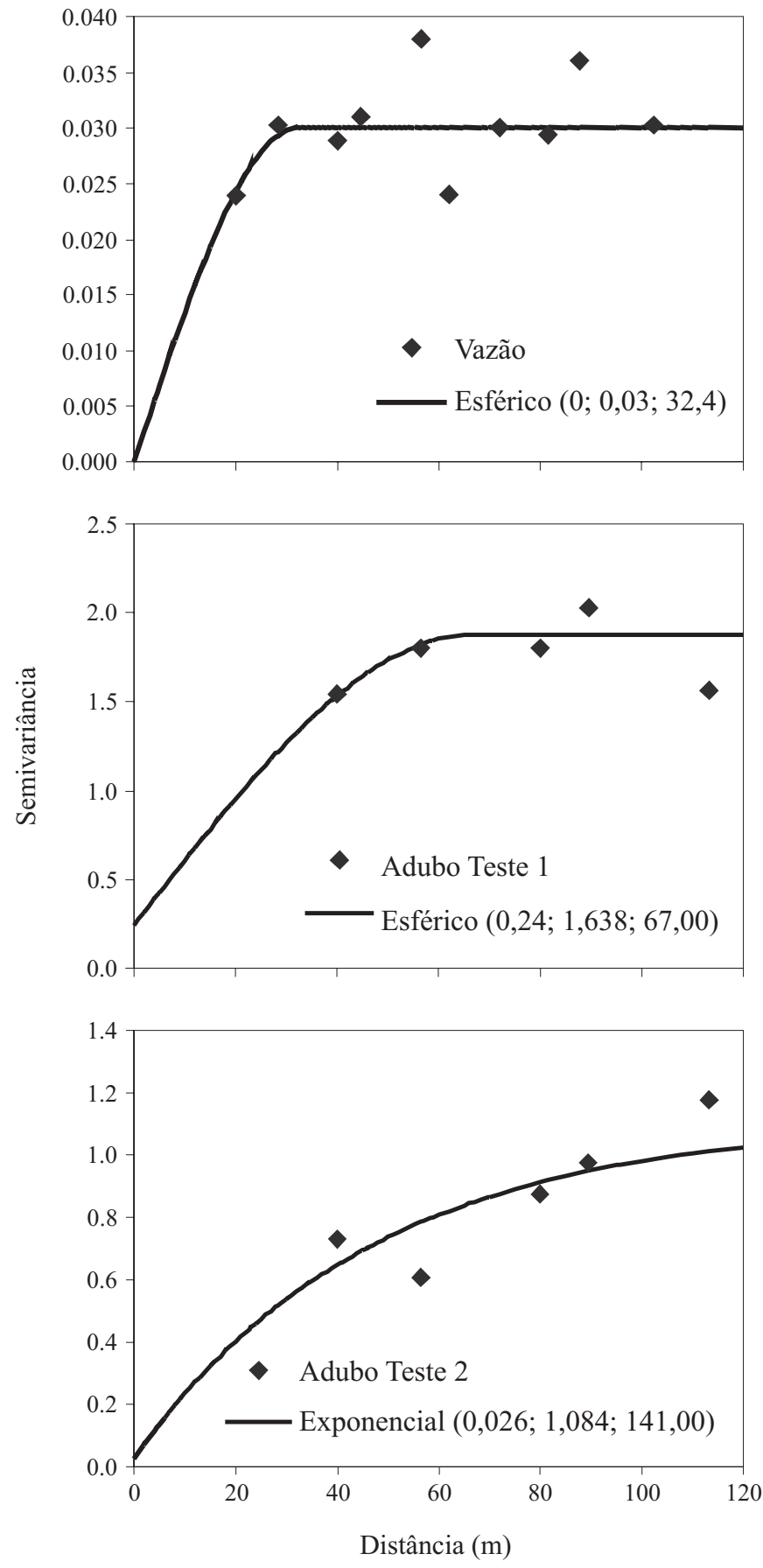

Figura 1. Semivariogramas experimentais dos dados de vazão dos gotejadores e quantidade de adubo aplicadas nos dois testes

também com maiores PNAC, PCOM e PMCOM, fato confirmado pela correlação significativa a $1 \%$ de probabilidade. A maior PMCOM causada pela maior disponibilidade de água, concorda com Medeiros et al. (2000) e Costa et al. (2002) que obtiveram maior peso médio de frutos comerciáveis e maior produtividade comerciável com maiores lâminas de irrigação.

As maiores vazões conferiram tendência de maior firmeza de frutos, concordando com Costa (1999) e Araújo (2000), e de menor espessura de polpa, como indicado pela correlação significativa a $10 \%$ de probabilidade. O maior desenvolvimento vegetativo devido às maiores vazões pode ter atra- sado o desenvolvimento dos frutos, porém Medeiros et al. (2000) constataram menor firmeza de frutos e menor teor de sólidos solúveis totais relacionados ao excesso de irrigação.

A elevação do terreno não teve amplitude suficiente para causar variação na vazão, mas se notou, por correlação significativa a $1 \%$ de probabilidade, que locais mais baixos tiveram frutos com maior PCOM e PMCOM e tendência a menores PNAC e firmeza, com $10 \%$ de probabilidade. A causa pode ser o acúmulo de umidade e nutrientes nas regiões mais baixas, conforme observaram Li et al. (2002), trabalhando com algodão.

A vazão dos gotejadores não autocompensantes diminuiu
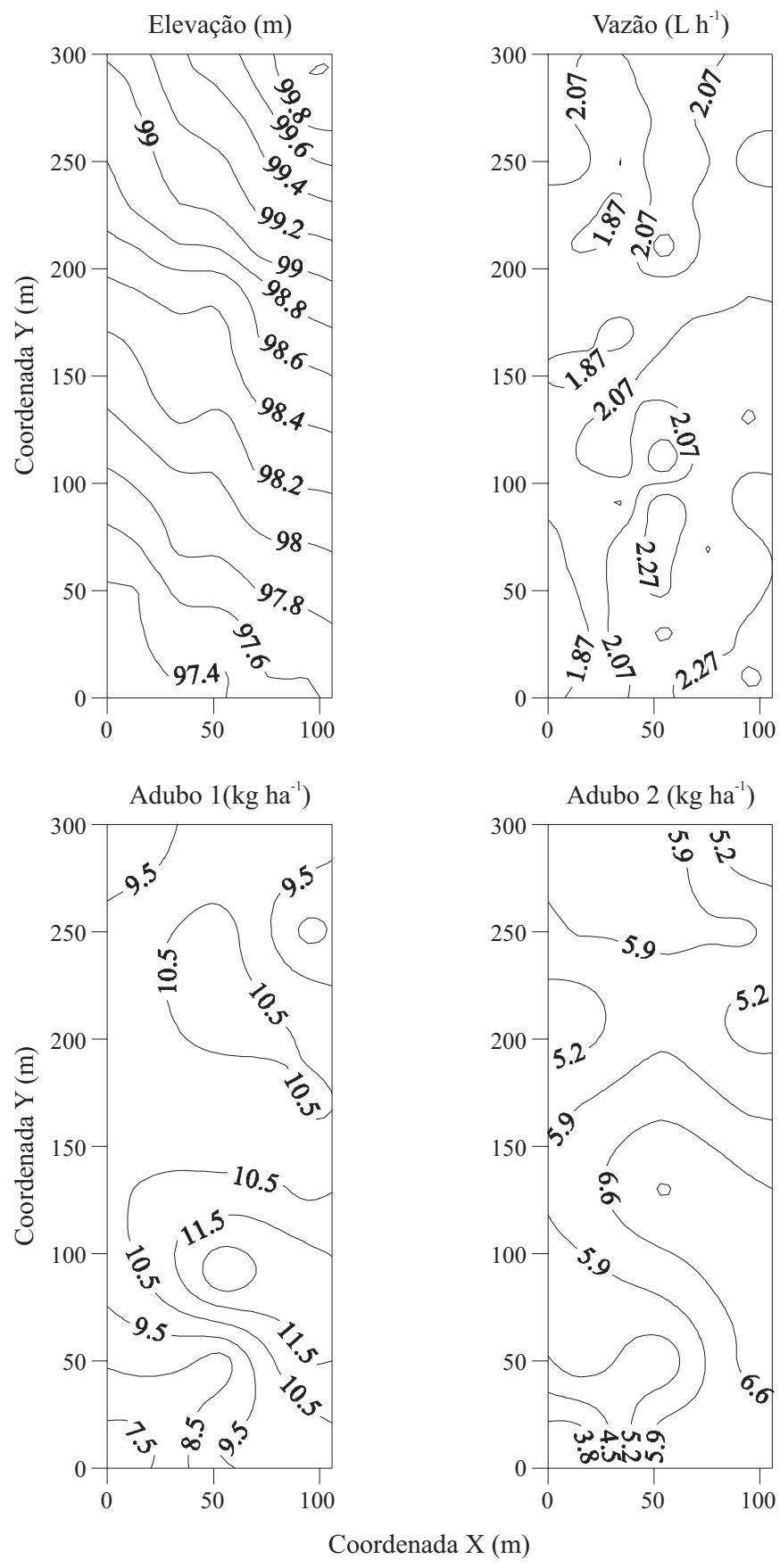

Figura 2. Mapas planialtimétrico e isolinhas da vazão dos gotejadores e quantidades de adubo aplicadas nos dois testes 
Tabela 4. Correlações de Spearman entre variáveis de produção e qualidade dos frutos de melão e características da fertirrigação na Fazenda São João em Mossoró, RN, 2002

\begin{tabular}{|c|c|c|c|c|c|}
\hline & VAZÃO & COTA $^{1}$ & DIST & $\mathrm{QAD}_{1}$ & $\mathrm{QAD}_{2}$ \\
\hline Vazão & - & $-0,17^{\mathrm{ns}}$ & $-0,23^{*}$ & $0,37^{+}$ & $0,44^{*}$ \\
\hline $\mathrm{QAD}^{1}$ & $0,48 *$ & $0,15^{\mathrm{ns}}$ & $-0,28^{\mathrm{ns}}$ & - & - \\
\hline$Q A D^{2}$ & $0,42^{*}$ & $-0,09^{n s}$ & $-0,31^{\mathrm{ns}}$ & - & - \\
\hline PEXP & $0,01^{\mathrm{ns}}$ & $-0,09^{n s}$ & $-0,32$ ** & $0,08^{\text {ns }}$ & $0,33^{\text {ns }}$ \\
\hline PNAC & $0,41^{* *}$ & $-0,21^{+}$ & $-0,10^{\mathrm{ns}}$ & $-0,19^{n s}$ & $0,14^{\mathrm{ns}}$ \\
\hline PCOM & $0,36^{\star *}$ & $-0,28^{* *}$ & $-0,39 * *$ & $-0,12^{\text {ns }}$ & $0,27^{\mathrm{ns}}$ \\
\hline PMCOM & 0,36 ** & $-0,28$ ** & $-0,39 * *$ & $-0,12^{\mathrm{ns}}$ & $0,27^{\mathrm{ns}}$ \\
\hline ESPOLP & $-0,22^{+}$ & $-0,11^{\mathrm{ns}}$ & $-0,04^{\mathrm{ns}}$ & $-0,43^{*}$ & $-0,22^{n s}$ \\
\hline Firmeza & $0,19^{+}$ & $-0,19^{+}$ & $-0,09^{n s}$ & $-0,04^{\mathrm{ns}}$ & $-0,03^{\text {ns }}$ \\
\hline SST & $-0,11^{\mathrm{ns}}$ & $0,03^{\mathrm{ns}}$ & $0,02^{n s}$ & $-0,06^{n s}$ & $-0,008^{n s}$ \\
\hline
\end{tabular}

** Significativo a 1\% de probabilidade; * Significativo a 5\%; ns Não significativo; + Significativo a 10\%; COTA - Elevaçáo do terreno; DIST - distancia ate a entrada de agua; QAD e QAD2 - Quantidades de adubo aplicadas; PEXP - Peso de frutos tipo exportação; PNAC - Peso de frutos tipo mercado nacional; de polpa: SST - Conteúdo de sólidos solúveis totais

(correlação significativa a 5\%) com o aumento da distância até as duas entradas de água (ordenadas X: 50 m e Y: 100 e 300 m). O déficit hídrico, devido à menor vazão nos locais mais distantes da entrada de água, prejudicou as variáveis PEXP, PCOM e PMCOM (1\% de probabilidade). A PNAC deve ter sido compensada em locais baixos pelo acúmulo de umidade e nutrientes, o que está de acordo com Barros (2002) que relaciona maior peso de frutos e maiores produções à maior disponibilidade hídrica.

A vazão foi a principal responsável pela variabilidade das quantidades de adubo aplicadas; enquanto a condutividade elétrica das soluções coletadas em todos os testes teve variabilidade muito baixa, a quantidade de adubo diminuiu nos locais em que as vazões foram menores (Figura 2). Os locais que receberam mais adubo no primeiro teste mostraram menores ESPOLP (significativo a 5\% de probabilidade), devido, talvez, a um desenvolvimento vegetativo maior das plantas e menor desenvolvimento dos frutos. A quantidade de adubo aplicada no segundo teste não influenciou significativamente as características de produção nem a qualidade dos frutos de melão; de modo semelhante, Li \& Rao (2003) observaram pequena influência da variabilidade da distribuição de fertilizantes sobre a produtividade de trigo.

As características mais importantes de qualidade, firmeza de frutos e sólidos solúveis totais, não sofreram influência significativa de nenhuma variável, concordando com Barros (2002) e confirmando a eficiência da seleção dos frutos, porém, considerando-se correlações a 10\% de probabilidade, as maiores firmezas são devidas às maiores vazões dos gotejadores, que podem ter aumentado o desenvolvimento vegetativo em detrimento do desenvolvimento dos frutos e pelo acúmulo de umidade e nutrientes nos locais mais baixos, influenciando negativamente a firmeza.

\section{CONCLUSÕES}

1. A vazão dos gotejadores apresentou variabilidade baixa e foi menor que o esperado.
2. As quantidades de adubo aplicadas tiveram variabilidades de baixas para médias e, em relação ao calculado, foram menores no primeiro teste e iguais no segundo.

3. A variação nas vazões foi a causa principal da variação nas quantidades de adubo aplicadas.

4. As uniformidades de emissão foram boas e excelentes para as vazões dos gotejadores e regulares e boas para as quantidades de adubo aplicadas, mesmo assim, a fertirrigação foi causa significativa de variabilidade espacial na produtividade e qualidade do melão.

5. Os valores de vazão e quantidade de adubo aplicado apresentaram forte dependência espacial e os mapas de isolinhas permitiram localizar-se as regiões do campo onde a irrigação e a adubação apresentaram déficit ou excesso.

6. As variações de vazão influenciaram positivamente a PNAC, a PCOM e o PMCOM, por outro lado, as variações nas quantidades de adubo aplicadas influenciaram negativamente a PEXP e a espessura de polpa dos frutos.

\section{AGRADECIMENTOS}

À CAPES, pelas bolsas concedidas; à Fundação Cearense de Apoio ao Desenvolvimento Científico e TecnológicoFUNCAP, pelo apoio financeiro, e à Fazenda São João Ltda, pelo uso de toda a estrutura experimental.

\section{LITERATURA CITADA}

Araújo, A. P. Cobertura do solo e métodos de plantio no cultivo do melão amarelo. Mossoró: ESAM, 2000. 49p. Dissertação Mestrado

ASAE - American Society of Agricultural Engeneers. Field evaluation of irrigation systems. In: ASAE Standards, St. Joseph: ASAE, 1994. p.760-765.

Barros, A. D. Manejo da irrigação por gotejamento, com diferentes níveis de salinidade da água, na cultura do melão. Botucatu: UNESP, 2002.124p. Tese Doutorado

Burt, C. M.; Clemmens, A. J.; Strelkoff, T. S.; Solomon, K. H.; Bliesner, R. D.; Hardy, L. A.; Howell, T. A.; Eisenhauer, D. E. Irrigation performance measures: efficiency and uniformity. Journal of Irrigation and Drainage Engineering, New York, v.123, n.6, p.423-447, 1997.

Clemmens, A. J.; Solomon, K. H. Estimation of global irrigation distribution uniformity. Journal of Irrigation and Drainage Engineering, New York, v.123, n.6, p.454-461, 1997.

Costa, F. A.; Medeiros, J. F.; Negreiros, M. Z.; Bezerra Neto, F.; Porto, D. R. Q.; Chaves, S. W. P.; Dantas, K. N. Rendimento de melão cantaloupe em diferentes coberturas de solo e lâminas de irrigação. Caatinga, Mossoró, v.15, n.1-2, p.49-55, 2002.

Costa, M. C. Efeitos de diferentes níveis de água com dois níveis de salinidade na cultura do meloeiro. Botucatu: UNESP, 1999. 115p. Tese Doutorado

Englund, E.; Sparks, A. Geo-EAS user’s guide. Las Vegas: U.S. Environmental Protection Agency, 1991. n. p. EPA/600/8-91/008.

Evans, R. G.; Han, S.; Kroeger, M. W. Spatial distribution and uniformity evaluations for chemigation with center pivots. Transactions of ASAE, St. Joseph, v.38, n.1, p.85-92, 1995. 
Fietz, C. R.; Folegatti, M. V.; Vieira, S. R.; Frizzone, J. A. Efeito da variabilidade do armazenamento de água no solo na qualidade da irrigação por aspersão. Revista Brasileira de Engenharia Agrícola e Ambiental, Campina Grande, v.3, n.2, p.150-153, 1999.

Fraisse, C. W.; Duke, H. R.; Heermann, D. F. Laboratory evaluation of variable water application with pulse irrigation. Transactions of ASAE, St. Joseph, v.38, n.5, p.1363-1369, 1995.

Frizzone, J. A. Uniformidade e eficiência de irrigação. Piracicaba: DER/ESALQ, 1992. 53p. Série Didática 003

Gonçalves, A. C. A.; Folegatti, M. V.; Vieira, S. R. Padrões de amostragem e intensidade de krigagem na caracterização do armazenamento de água no solo, em área irrigada por pivô central. Revista Brasileira da Ciência do Solo, Viçosa, v.23, n.3, p.485-495, 1999.

Li, H.; Lascano, R. J.; Booker, J.; Wilson, L. T.; Bronson, K. F.; Segarra, E. State-space description of field heterogeneity: water and nitrogen use in cotton. Soil Science Society of America Journal, Madison, v.66, n.2, p.585-595, 2002.

Li, J.; Rao, M. Field evaluation of crop yield as affected by non uniformity of sprinkler-applied water and fertilizers. Agricultural Water Management, Amsterdam, v.59, n.1, p.1-13, 2003.

Mantovani, E. C.; Villalobos, F. J.; Orgaz, F.; Fereres, E. Modeling the effects of sprinkler irrigation unifomity on crop yield. Agricultural Water Management, Amsterdam, v.27, n.3-4, p.243-257, 1995.

Medeiros, J. F.; Nascimento, I. B.; Costa, M. C.; Scaloppi, E. J. Produção de melão sob diferentes lâminas de irrigação com dois níveis de salinidade. Horticultura Brasileira, Brasília, v.18, p.612-614, 2000.

Pannatier, Y. Variowin. Software for spatial data analysis in 2D. New York: Springer-Verlag, 1996. 91p.

Pinto, J. M.; Soares, J. M.; Nascimento, T. Análise de coeficientes de uniformidade de distribuição de água em sistema de irrigação localizada. In: Congresso Nacional de Irrigação e Drenagem, 8, 1988, Florianópolis. Anais...Florianópolis: ABID, 1988. p.309-326.
Plant, R. E.; Mermer, A.; Pettygrove, G. S.; Vayssieres, M. P.; Young, J. A.; Miller, R. O.; Jackson, L. F.; Denison, R. F.; Phelps, K. Factors underlying grains yield spatial variability in three irrigated wheat fields. Transactions of the ASAE, St. Joseph, v.42, n.5, p.1187-1202, 1999.

Sadler, E. J.; Camp, C. R.; Evans, D. E.; Millen, J. A. Spatial variation of corn response to irrigations. Transactions of ASAE, St. Joseph, v.45, n.6, p.1869-1881, 2002.

Sampaio, S. C.; Faria, M. A.; Lima, L. A.; Oliveira, M. S. Fertirrigação simulada em linhas de gotejadores. Engenharia Rural, Piracicaba, v.7, n.1, 51-61, 1996.

Seginer, I. A note on the economic significance of uniform water application. Irrigation Science, New York, v.1, n.1, p.19-25, 1978.

Solomon, K. Manufacturing variation of trickle emitters. Transactions of ASAE, St. Joseph, v.22, n.5, p.1034-1038, 1979.

Souza, V. F.; Folegatti, M. V.; Frizzone, J. A.; Corrêa, R. A. L.; Alencar, C. M. Distribuição de fertilizantes em um sistema de fertigação por gotejamento. Revista Brasileira de Engenharia Agrícola e Ambiental, Campina Grande, v.7, n.1, p.186189, 2003.

Upadhyaya, S. K.; Rosa, U. A.; Ehsani, M.; Koller, M.; Josiah, M.; Shikanai, T. Precision farming in a tomato production system. ASAE paper n. 991147. St. Joseph: ASAE, 1999. 23p.

Walker, W. Explicit sprinkler irrigation uniformity: efficiency model. Journal of Irrigation and Drainage Division, New York, v.105, n.IR2, p.129-137, 1979.

Warrick, A. W.; Hart, W. E.; Yitayew, M. Calculation of distribution and efficiency for nonuniform irrigation. Journal of Irrigation and Drainage Engineering, New York, v.115, n.4, p.674686, 1987.

Zanini, J. R.; Olitta, A. F. L. Comparação de distribuição de fertilizante aplicado por tanque de derivação de fluxo e por bomba injetora, na fertirrigação por gotejamento. In: Congresso Brasileiro de Engenharia Agrícola, 16, 1987, Jundiaí. Anais... Jundiaí: SBEA/DEA-IAC, 1987. p.77-92. 